\title{
SEASONAL DYNAMICS OF PHLEBOTOMUS PAPATASI (SCOPOLI, 1786) (DIPTERA: PSYCHODIDAE) POPULATION IN SOUTHERN REPUBLIC OF MOLDOVA
}

\author{
Tatiana Şuleşco
}

Institute of Zoology, Chisinau, Republic of Moldova, e-mail: tatiana_sulesco@yahoo.com

\begin{abstract}
Phlebotomine sand flies are vectors of several infectious pathogens, including parasitic protozoans of the genus Leishmania and phleboviruses. Increasing sand fly biting nuisance reported by residents from southern Republic of Moldova since 2011 initiated this study. Ceadir-Lunga, a semi-urban locality in southern Republic of Moldova was selected for seasonal sand fly collections outdoors and indoors in 2015 and 2017 using CDC light traps and manual aspirators. Continuous trapping showed markedly longer activity of P. papatasi indoors. Specimens were collected from first aspirations in the second half of June until last collections in mid-September, suggesting that the actual indoor activity of P. papatasi may have been longer. Low numbers of trapped specimens do not allow make accurate conclusions regarding the seasonal dynamics.
\end{abstract}

\section{Introduction}

Phlebotomine sand flies (Diptera: Psychodidae) are vectors of several infectious pathogens, including parasitic protozoans of the genus Leishmania and phleboviruses [1]. Republic of Moldova is considered a country non-endemic for leishmaniasis, there are no records of autochthonous human or canine cases [2]. In the past, presence of three Phlebotomus species was reported in Moldova: Phlebotomus papatasi (Scopoli, 1786), P. perfiliewi Parrot, 1930 and $P$. chinensis (Newstead, 1916) [4, 5]. However, the historical studies provided scarse information about their abundance and seasonal dynamics. Historical data mentioned low numbers of $P$. papatasi ( 5 females and 2 males) in Giurgiulesti village, Cahul district, southern Moldova in 1946. In 1947, sand fly surveillance revealed the presence of low numbers of $P$. papatasi in other villages located in Cahul district (Chislita-Prut, Colibasi, Vadul-lui-Isac, Manta, Crihana Veche villages and Cahul town), but no exact numbers were given. Only one P. papatasi male was caught in Chisinau city in 1947 [6]. After several decades, increasing sand fly biting nuisance reported by residents from southern Moldova since 2011 initiated this study.

\section{Materials and methods}

Ceadir-Lunga (WGS84 coordinates: 46o06549N, 28084219E), a semi-urban locality in southern Moldova was selected for seasonal sand fly collections in 2015 and 2017 using Centre for Disease Control (CDC) light traps (Trappola per Monitoraggio Zanzare, IMT Original 2002, Italy), miniature CDC light traps (John W. Hock Company, model 512, Gainesville, Florida, U.S.A.) and manual aspirators. Two CDC light traps operated on two permanent sites in Ceadir-Lunga close to two poultry houses between June 22 and September 26, 2015. Each site was sampled 2-3 times per week. Collection by manual aspirators inside houses $(\mathrm{n}=13)$ 
and animal shelters $(n=14)$ was conducted several times per week between June 26 and September 14, 2015. Every time one house and/or one animal shelter were visited. In 2017, two CDC light traps operated every week on the permanent sites between July 6 and September 25. Additionally, sand flies were collected manually inside a chicken coop and a house (July $30-31,2017)$. The collected insects were killed by freezing at $-20 \mathrm{oC}$ and preserved in $96 \%$ ethanol. For morphological identification, head and genitalia of each specimen were dissected and mounted on slides using Berlese mounting medium. Species identification was performed using published key [3].

\section{Results and discussions}

A total of 225 and 47 sand flies were sampled in 2015 and 2017, respectively, in the locality Ceadir-Lunga. In total, 18 specimens were trapped using CDC traps between June 22 and September 26, 2015. The majority of specimens belonged to P. papatasi (4 males, 5 females). First specimens of P. papatasi were trapped in mid-July and last in mid-August (Figure 1). Collection by manual aspirators inside houses and animals shelters between June 26 and September 14, 2015 yielded 207 sand flies (140 specimens in the houses and 67 specimens in animal shelters). The highest number of $P$. papatasi (49 males, 108 females) was collected in July in hen houses. Indoor sand fly activity was markedly longer, first specimens being collected at first aspiration in June 24 and last in September 14.
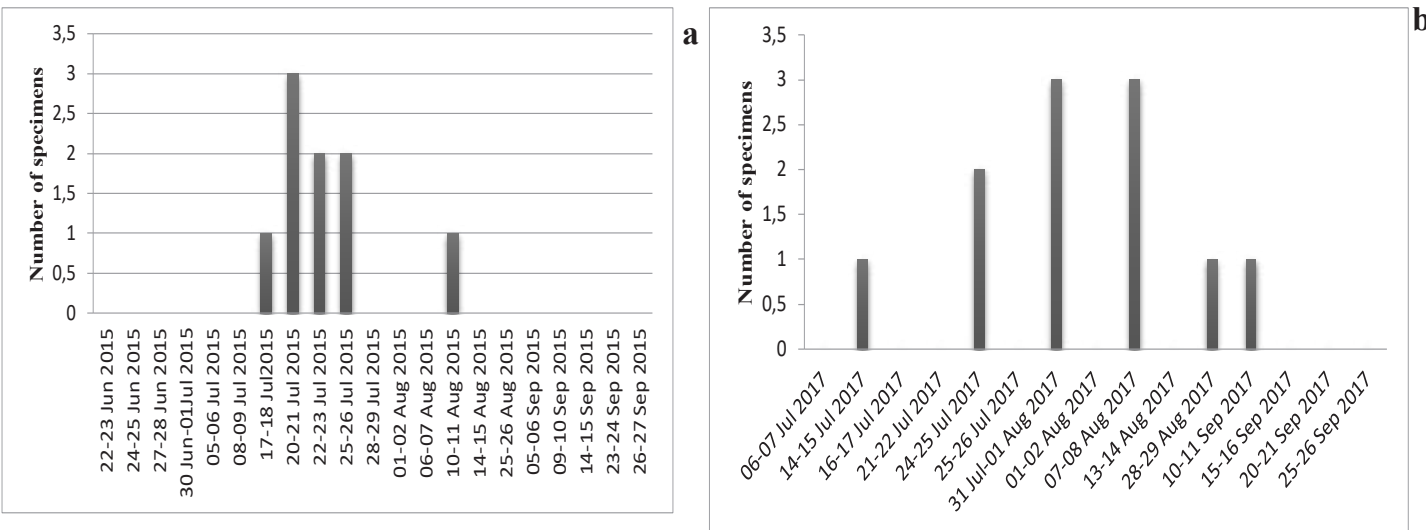

Figure 1. Seasonal collections of P. papatasi using CDC light traps in Ceadir-Lunga: b - collections conducted in 2017

In 2017, a total of 18 sand flies were collected by two CDC light traps, operated on the permanent sites between July 6 and September 25. The majority of specimens belonged to P. papatasi (3 males, 3 females) was collected in July. Four specimens of P. papatasi were sampled in August and one specimen in September 2017. Manual collection of sand flies inside a chicken coop and a house (July 30-31, 2017) provided additional 29 P. papatasi specimens (12 males, 17 females). Numbers of specimens trapped by the CDC traps in 2015 and 2017 are shown on graphs (Figure 1). 
Continuous trapping in Ceadir-Lunga in 2015 and 2017 showed markedly longer activity of P. papatasi indoors. Specimens were collected from first aspirations in the second half of June until last collections in mid-September, suggesting that the actual indoor activity of $P$. papatasi may have been longer. First specimens from outdoor trapping were collected in early July, despite earlier trapping effort. In 2015, no specimens were trapped outdoors after mid-August and in 2017, outdoor activity ceased by mid-September, despite later trapping effort. Low numbers of trapped specimens do not allow to make accurate conclusions regarding the seasonal dynamics.

This study was supported by funds from the Institute of Zoology, Republic of Moldova (15.817.02.12F; 20.80009.7007.02).

\section{Bibliography}

1. Maroli M., Feliciangeli M. D., Bichaud L., Charrel R., Gradoni L. Phlebotomine sand flies and the spreading of leishmaniases and other diseases of public health concern. In: Med Vet Entomol., 2013, 27(2), p. 123-47.

2. Mihalca A. D., Cazan C. D., Sulesco T., Dumitrache O. M. A historical review on vector distribution and epidemiology of human and animal leishmanioses in Eastern Europe. In: Res. Vet. Sci., 2019, 123, p. 185-191.

3. Perfiliev P. P. Phlebotominae. Jerusalem: Israel Program of Scientific Translations, 1968.

4. Petrishcheva P. A. A study of sand flies (fam. Phlebotomidae) in the USSR. In: Parazitologiya, 1967, 1(6), p. 455-464.

5. Petrishcheva P. A. Carriers of pathogens of natural focal diseases. Moscow: MEDGIZ, 1962.

6. Sinelschikov V. A. Sand flies of southern Moldavia. In: Paraziti zivotnih i rastenii, 1973, 9, p. 226-229. 